a major tourist destination, and during New Year's Eve, there are many festivities. The AZ Sint-Jan is the largest hospital providing medical care to the area.

Aim: To examine the impact of the New Year's Eve festivities on the workload of the emergency department of AZ Sint-Jan. Methods: Data was analyzed for every patient presenting to the emergency department from the $31^{\text {st }}$ of December starting from 06:00 PM until the $1^{\text {st }}$ of January 08:00 AM from 2009 until 2018. The time of entry, type of injury, gender, age, and whether the patient was intoxicated were evaluated. Ten other dates in this time period were obtained for comparison via a random date generator. Data were analyzed using Jasp(C)

Results: There were 826 patients included for analysis. On average, 41 patients presented themselves to the emergency department on New Year's Eve between 06:00 PM and 08:00 AM. On a random day, there were only 31 patients. Most of the patients on New Year's Eve arrived between 00:00 AM and 08:00 AM. 57\% of all patients were male. $22 \%$ of all patients were intoxicated with alcohol. From 00:00 AM until 08:00 AM, one in three patients were intoxicated. The average age on admission was 36 years.

Discussion: During New Year's Eve there is a consistently higher workload in the emergency department. There is an influx of young males who are intoxicated. These patients tend to stay a long time to "sleep it off" and put considerable stress on the available resources. More attention should be given to risk mitigation strategies tailored to this group to prevent excessive drinking.

Prehosp Disaster Med 2019;34(Suppl. 1):s133-s134

doi:10.1017/S1049023X19002929

Health Care Provision during a Sporting Mass Gathering: A Structure and Process Description of On-Site Care Delivery Dr. Amy Johnston 1,2,5, Jasmine Wadham², Josea Polong-Brown ${ }^{2}$, Dr. Michael Aitken 2,3, Dr. Jamie Ranse 2,3, Prof. Alison Hutton ${ }^{4}$, Dr. Brent Richards, Prof. Julia Crilly ${ }^{2,3}$

1. Department of Emergency Medicine, Princess Alexandra Hospital, and University of Queensland, Woollongabba, Brisbane, Australia

2. Department of Emergency Medicine, Gold Coast Hospital and Health Service, Southport, Australia

3. Menzies Health Institute Queensland, Griffith University, Gold Coast, Australia

4. School of Nursing, University of Newcastle, Newcastle, Australia

5. Intensive Care Unit, Gold Coast Hospital and Health Service, Southport, Australia

Introduction: During mass gatherings, such as marathons, the provision of timely access to health care services is required for the mass gathering population as well as the local community. However, effective provision of health care during sporting mass gatherings is not well understood.

Aim: To describe the structures and processes developed for an emergency team to operate an in-event acute health care facility during one of the largest mass sporting participation events in the southern hemisphere, the Gold Coast marathon.

Methods: A pragmatic qualitative methodology was used to describe the structures and processes required to operate an in-event acute health care facility providing services for marathon runners and spectators. Content analysis from 12 semi-structured interviews with Emergency Department (ED) clinical staff working during the two-day event was undertaken in 2016.

Results: Structural elements that underpinned the in-event health care facility included: physical spaces such as the clinical zones in the marathon health tent, tent access, and egress points; and resources such as bilingual staff, senior medical staff, and equipment such as electrocardiograms. Critical processes included: clear communication pathways, interprofessional care coordination, and engagement involving shared knowledge of and access to resources. Distinct but overlapping clinical scope between nurses and doctors was also noted as important for timely care provision and appropriate case management. Staff outlined many perceived benefits and opportunities of in-event health care delivery including ED avoidance and disaster training.

Discussion: This in-event model of emergency care delivery enabled acute out-of-hospital health care to be delivered in a portable and transportable facility. Clinical staff reported satisfaction with their ability to provide a meaningful contribution to hospital avoidance and to the local community. With the number of sporting mass gatherings increasing, this temporary, inevent model of health care provision is one option for event and health care planners to consider.

Prehosp Disaster Med 2019;34(Suppl. 1):s134

doi:10.1017/S1049023X19002930

\section{Health Needs Assessment in Disasters by Emergency Medical Teams in the ASEAN Region \\ Mr. Yosuke Takada ${ }^{1,2}$, Dr. Kanin Keeratipongpaiboon ${ }^{1}, A R C H$ Project Expert Team ${ }^{1}$ \\ 1. ARCH Project, Kobe, Japan \\ 2. Dentistry and Pharmaceutical Sciences, Okayama University Graduate School of Medical, Okayama, Japan}

Introduction: Japan International Cooperation Agency has started the project for strengthening the ASEAN regional capacity on disaster health management (ARCH Project) since 2016. This project conducted the start-up regional collaboration drill in ASEAN. All participants from ASEAN countries realized the need for a standardized assessment tool. Several UN agencies and international organizations launched assessment tools, but there is no standard assessment tool.

Aim: To develop an integrated rapid health needs assessment (HNA) tool in the ASEAN region. This paper reports the development process of the HNA tool.

Methods: The project established the project working group (PWG) to developing some tools. PWG consisted of the expert team, project team, Japanese Advisory group and twenty delegates from ten ASEAN member states. PWG established the cycle of the developing process of the HNA tool.

Results: We created a health needs assessment form and a summary form. The assessment form consists of (1) Informant information, (2) Site information, (3) Overall situation of the site, (4) Public health, (5) Health facility damage. The summary form consists of (1) Informant information, (2) Site information, (3) Critical areas for support, (4) Situation of the site. 